Article

\title{
Simultaneous Quantification of Four Phenylethanoid Glycosides in Rat Plasma by UPLC-MS/MS and Its Application to a Pharmacokinetic Study of Acanthus Ilicifolius Herb
}

\author{
Mengqi Zhang ${ }^{1,2, \dagger}$, Xia Ren ${ }^{1,2, \dagger}$, Shijun Yue ${ }^{1,2} \oplus$, Qing Zhao ${ }^{1,2}$, Changlun Shao ${ }^{1,2, *}$ and \\ Changyun Wang ${ }^{1,2, *}$ \\ 1 Key Laboratory of Marine Drugs, The Ministry of Education of China, School of Medicine and Pharmacy, \\ Ocean University of China, Qingdao 266003, China \\ 2 Laboratory for Marine Drugs and Bioproducts, Qingdao National Laboratory for Marine Science and \\ Technology, Qingdao 266237, China \\ * Correspondence: shaochanglun@ouc.edu.cn (C.S.); changyun@ouc.edu.cn (C.W.); \\ Tel.: +86-532-8203-1381 (C.S.); +86-532-8203-1536 (C.W.); Fax: +86-532-8203-1536 (C.S. \& C.W.) \\ + Contributed equally.
}

Academic Editors: In-Soo Yoon and Hyun-Jong Cho

Received: 29 June 2019; Accepted: 19 August 2019; Published: 28 August 2019

\begin{abstract}
Acanthus ilicifolius herb (AIH), the dry plant of Acanthus ilicifolius L., has long been used as a folk medicine for treating acute and chronic hepatitis. Phenylethanoid glycosides (PhGs) are one family of the main components in AIH with hepatoprotective, antioxidant, and anti-inflammatory activities. In this study, the pharmacokinetics of AIH was investigated preliminarily by ultra-performance liquid chromatography coupled with triple quadrupole mass spectrometry (UPLC-MS/MS). A simultaneously quantitative determination method for four PhGs (acteoside, isoacteoside, martynoside, and crenatoside) in rat plasma was first established by UPLC-MS/MS. These four PhGs were separated with an ACQUITY UPLC BEH $C_{18}$ column $(2.1 \times 50 \mathrm{~mm}, 1.7 \mu \mathrm{m})$ by gradient elution (mobile phase: $\mathrm{MeCN}$ and $0.1 \%$ formic acid in water, $0.4 \mathrm{~mL} / \mathrm{min}$ ). The mass spectrometry detection was performed using negative electrospray ionization $\left(\mathrm{ESI}^{-}\right)$in multiple reaction monitoring (MRM) mode. By the established method, the preliminary pharmacokinetics of AIH was elucidated using the kinetic parameters of the four PhGs in rat plasma after intragastric administration of AIH ethanol extract. All four PhGs showed double peaks on concentration-time curves, approximately at $0.5 \mathrm{~h}$ and $6 \mathrm{~h}$, respectively. Their elimination half-lives $\left(t_{1 / 2}\right)$ were different, ranging from $3.42 \mathrm{~h}$ to $8.99 \mathrm{~h}$, although they shared similar molecular structures. This work may provide a basis for the elucidation of the pharmacokinetic characteristics of bioactive components from $\mathrm{AIH}$.
\end{abstract}

Keywords: acanthus ilicifolius herb; phenylethanoid glycosides; pharmacokinetics; UPLC-MS/MS

\section{Introduction}

Acanthus ilicifolius L. is a mangrove shrub belonging to the Acanthus genus in the Acanthaceae family which grows in tropical and subtropical intertidal habitats. Acanthus ilicifolius herb (AIH, "laoshule" in Chinese), the dry plant of A. ilicifolius L., is a folk medicine to treat acute and chronic hepatitis, lymphatic intumescence, spleen enlargement, paralysis, and rheumatism [1-6]. Modern pharmaceutical studies have demonstrated that the extracts of AIH possess hepatoprotective, antioxidant, anti-inflammatory, anticarcinogenic, and antibacterial activities [6-10]. Numerous chemical constituents have been isolated from $\mathrm{AIH}$, including phenylethanoid glycosides (PhGs), alkaloids, flavones, lignans, triterpenoid saponins, and sterols [11-17]. Among them, PhGs were reported as one family of the main components 
from $\mathrm{AIH}$, such as acteoside, isoacteoside, martynoside, and crenatoside with potential pharmacological effects [18-23]. The pharmacologic actions of AIH extracts, as well as these four PhGs, have been reported, whereas no pharmacokinetics have been studied till now.

During our ongoing research of pharmacodynamic material basis of medical plants, we found that $\mathrm{AIH}$ and its efficient components, PhGs, exhibited potent hepatoprotective, antiviral, and antioxidant activities. Specifically, PhGs were found to be abundant in $\mathrm{AIH}$, of which acteoside and isoacteoside were the main components, while martynoside and crenatoside were in relatively lower contents. In the present study, the pharmacokinetics of AIH were investigated with these four PhGs as representatives in rat plasma after intragastric administration of AIH extract. To achieve this purpose, a simple, sensitive and rapid ultra-performance liquid chromatography coupled with triple quadrupole mass spectrometry (UPLC-MS/MS) method was established, first, for the simultaneous and quantitative determination of the four PhGs in rat plasma. Herein, we report the establishment and optimization of UPLC-MS/MS method, the validation of the established method, and the pharmacokinetic study of AIH.

\section{Results and Discussion}

\subsection{Establishment and Optimization of the UPLC-MS/MS Method}

The UPLC-MS/MS method was established and optimized to determine the four PhGs (acteoside, isoacteoside, martynoside, and crenatoside) simultaneously and quantitatively. In preliminary experiments, the two isomer analytes, acteoside and isoacteoside, were found to have the same MS fragmentation characteristics. Therefore, it was required to separate these two analytes from each other by UPLC because of their influence on each other. In our study, different mobile phase compositions were screened, including methanol and water, methanol and $0.1 \%$ formic acid in water, $\mathrm{MeCN}$ and water, $\mathrm{MeCN}$ and $0.1 \%$ formic acid in water, and $\mathrm{MeCN}$ and $0.5 \%$ formic acid in water. It was found that the mobile phase consisting of $\mathrm{MeCN}$ and $0.1 \%$ formic acid in water significantly improved the peak shapes and achieved the baseline separation of acteoside and isoacteoside (Figure 1). Moreover, in comparison with isocratic elution, the gradient elution with $\mathrm{MeCN}$ and $0.1 \%$ formic acid shortened analysis duration and increased separation efficiency.

A
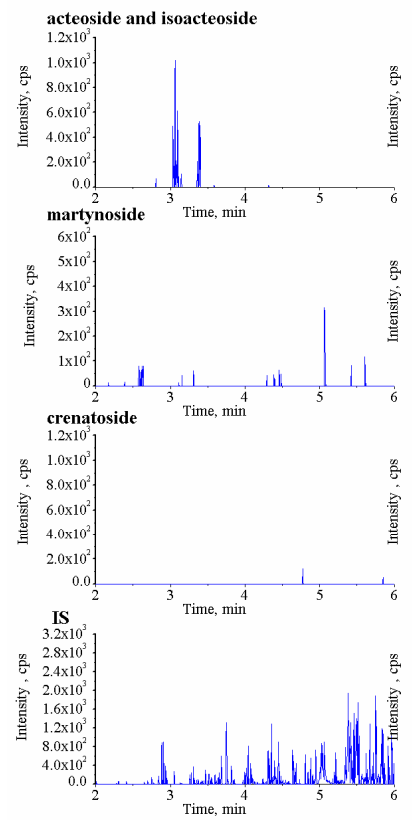

B
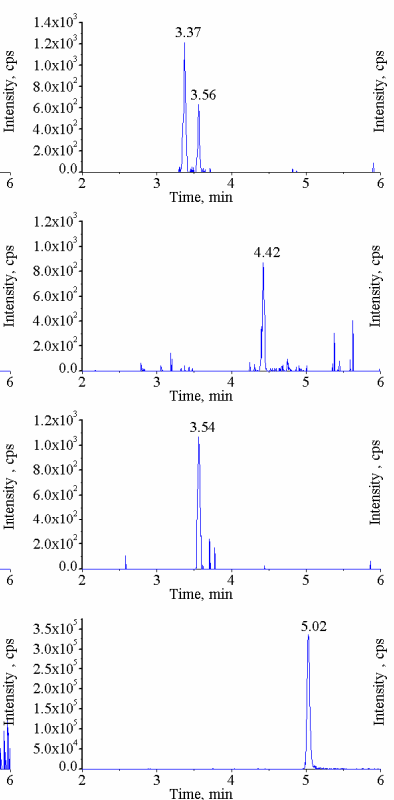

$\mathrm{C}$


Figure 1. The multiple reaction monitoring (MRM) chromatograms for the four phenylethanoid glycosides (PhGs) and genistein (IS) in (A) blank plasma, (B) blank plasma spiked with the four PhGs at the lowest limit of quantification (LLOQ) and IS (1000 ng/mL), and (C) test plasma collected at $30 \mathrm{~min}$ after intragastric administration. 
The mass conditions were modified to find the optimum precursor-to-product ion pairs for MRM detection by the production scan procedure. Both positive and negative ionization ESI modes were tested for the four PhGs and genistein (IS). It was observed that the negative mode (ESI ${ }^{-}$) of the four PhGs achieved better sensitivity as compared with the positive mode. Among them, acteoside, isoacteoside, and crenatoside displayed the same characteristic MS fragments of $\mathrm{m} / \mathrm{z} 161.02$ in the mass spectra due to their similar molecular structures (Figure 2 and Table 1).
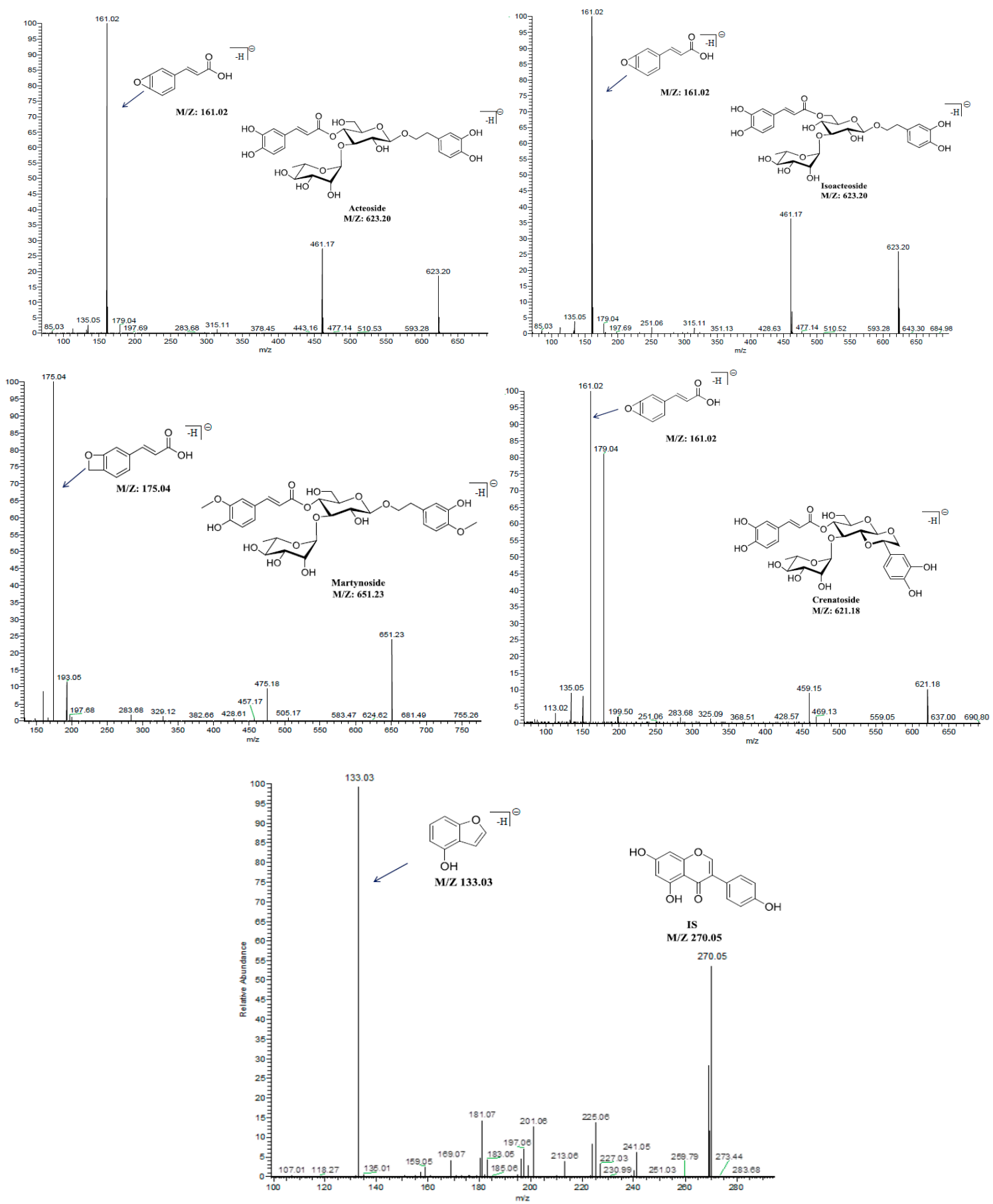

Figure 2. The structures, conjectural fragments, and MS/MS spectra of PhGs and IS at $30 \mathrm{~V}$ collision energy. 
Table 1. The optimized mass spectrometry parameters of the PhGs and IS.

\begin{tabular}{ccccc}
\hline Components & Retention Time (min) & $\begin{array}{c}\text { MRM Transitions } \\
\text { (precursor } \rightarrow \text { product) }\end{array}$ & Collision Energy (v) & Cone Voltage (v) \\
\hline Acteoside & 3.37 & $623.2 \rightarrow 161.0$ & 50 & 76 \\
Isoacteoside & 3.56 & $623.2 \rightarrow 161.0$ & 50 & 76 \\
Martynoside & 4.42 & $651.2 \rightarrow 175.0$ & 36 & 78 \\
Crenatoside & 3.54 & $621.2 \rightarrow 161.0$ & 44 & 72 \\
Genistein (IS) & 5.02 & $270.0 \rightarrow 133.0$ & 34 & 78 \\
\hline
\end{tabular}

It should be pointed that genistein was selected as the IS because it displayed a strong MS response under negative ion mode $\left(\mathrm{ESI}^{-}\right)$and presented satisfactory chromatographic behavior (Figure 2 and Table 1).

\subsection{Contents of the Four PhGs in AIH}

The contents of the four PhGs were analyzed by UPLC-MS/MS utilizing the same chromatography method as described in Section 3.6. The contents of acteoside, isoacteoside, martynoside, and crenatoside in AIH ranged from 0.02 to $6.24 \mathrm{mg} / \mathrm{g}$ (Table 2).

Table 2. Contents of the four PhGs in AIH (means \pm SD).

\begin{tabular}{cc}
\hline Components & Contents $(\mathbf{m g} / \mathbf{g})$ \\
\hline Acteoside & $6.245 \pm 0.723$ \\
Isoacteoside & $0.822 \pm 0.102$ \\
Martynoside & $0.071 \pm 0.023$ \\
Crenatoside & $0.023 \pm 0.008$ \\
\hline
\end{tabular}

\subsection{Method Validation}

The established UPLC-MS/MS method was validated for its selectivity, linearity, accuracy, precision, extraction recovery, matrix effect, and stability according to the FDA Guidance for Industry on Bioanalytical Method Validation [24].

\subsubsection{Selectivity}

Representative chromatograms of the blank plasma sample, blank plasma sample added with PhGs at the lowest limit of quantification (LLOQ) and IS, and treated plasma samples are shown in Figure 1. The results suggest that no significant endogenous interference was found around the retention time of the PhGs and IS.

\subsubsection{Linearity and LLOQ}

The concentrations of PhGs in test samples were calculated by the calibration curves, which showed good linearities with $r^{2}>0.993$. The LLOQ of the four PhGs were determined ranging from 0.2 to $2.0 \mathrm{ng} / \mathrm{mL}$ in accordance with the signal-to-noise ratios (S:N) $>10$ (Table 3). These results indicated that the linearity and LLOQ were feasible for quantificational detection of the four PhGs in rat plasma.

Table 3. Regression equation and LLOQ for the four PhGs.

\begin{tabular}{ccccc}
\hline Components & Linear Regression Equation & $r^{\mathbf{2}}$ & Range $(\mathbf{n g} / \mathbf{m L})$ & LLOQ $(\mathbf{n g} / \mathbf{m L})$ \\
\hline Acteoside & $\mathrm{y}=0.000655 \mathrm{x}-0.001804$ & 0.9979 & $2.0-1000$ & 2.0 \\
Isoacteoside & $\mathrm{y}=0.000917 \mathrm{x}-0.000488$ & 0.9935 & $0.2-100$ & 0.2 \\
Martynoside & $\mathrm{y}=0.005864 \mathrm{x}-0.001393$ & 0.9990 & $0.4-200$ & 0.4 \\
Crenatoside & $\mathrm{y}=0.000592 \mathrm{x}-0.000034$ & 0.9949 & $0.4-200$ & 0.4 \\
\hline
\end{tabular}




\subsubsection{Accuracy and Precision}

Our results showed that the intra- and inter-day accuracies of the four PhGs ranged from $-8.92 \%$ to $9.88 \%$, while the precisions ranged from $1.47 \%$ to $13.08 \%$ (Table 4 ), indicating that the method had satisfactory accuracy and precision.

Table 4. Accuracy and precision of the four PhGs in rat plasma $(n=6)$.

\begin{tabular}{lccccc}
\hline \multirow{2}{*}{ Components } & Concentration $\mathbf{( n g} / \mathbf{m L})$ & \multicolumn{2}{c}{ Accuracy $\mathbf{( R E} \%)$} & \multicolumn{2}{c}{ Precision (RSD\%) } \\
\cline { 3 - 6 } & & Intra-day & Inter-day & Intra-day & Inter-day \\
\hline \multirow{3}{*}{ Acteoside } & 2.0 & 4.36 & 5.53 & 7.24 & 6.17 \\
& 5.0 & -5.26 & -3.81 & 2.17 & 3.60 \\
& 50.0 & -7.25 & -4.89 & 7.32 & 2.37 \\
Isoacteoside & 800.0 & 4.70 & 4.27 & 7.04 & 5.90 \\
& 0.2 & 9.88 & -4.86 & 6.42 & 3.80 \\
& 0.5 & 2.98 & -0.98 & 5.53 & 8.46 \\
Martynoside & 5.0 & 4.24 & -4.38 & 8.35 & 11.90 \\
& 80.0 & 9.26 & 7.27 & 8.27 & 9.47 \\
& 0.4 & -7.24 & 4.18 & 5.54 & 10.00 \\
& 1.0 & 2.04 & 3.41 & 9.09 & 10.49 \\
Crenatoside & 10.0 & -1.02 & 1.54 & 2.70 & 1.80 \\
& 160.0 & 1.44 & -2.71 & 1.47 & 3.39 \\
& 0.4 & 9.43 & 6.63 & 9.72 & 6.42 \\
& 1.0 & -8.53 & -5.12 & 12.37 & 13.08 \\
& 10.0 & -5.32 & -8.92 & 2.08 & 8.10 \\
& 160 & -2.95 & -5.22 & 6.39 & 4.35 \\
\hline
\end{tabular}

\subsubsection{Extraction Recovery and Matrix Effect}

It was found that the extraction recoveries of the four PhGs ranged from $70.56 \%$ to $104.54 \%$ at three concentration levels (Table 5). It should be noted that there were large variations of extraction recovery for acteoside and isoacteoside. The reason may be that the extraction recoveries of acteoside and isoacteoside suffered from low to moderate suppression due to matrix effects, which would not limit the use of this method, given the satisfactory precision and reproducibility obtained.

Table 5. The extraction recovery and matrix effects of the four PhGs in rat plasma $(n=6)$.

\begin{tabular}{|c|c|c|c|c|c|c|c|c|}
\hline \multirow{2}{*}{ Components } & \multirow{2}{*}{$\begin{array}{l}\text { Concentration } \\
(\mathrm{ng} / \mathrm{mL})\end{array}$} & \multicolumn{2}{|c|}{ Extraction Recovery } & \multicolumn{2}{|c|}{ Absolute Matrix Effect } & \multirow{2}{*}{$\begin{array}{c}\begin{array}{c}\text { Relative Matrix } \\
\text { Effect }\end{array} \\
\text { RSD (\%) }\end{array}$} & \multicolumn{2}{|c|}{ IS Normalized MF } \\
\hline & & Mean (\%) & RSD (\%) & Mean $(\%)$ & RSD (\%) & & Mean \pm SD & RSD (\%) \\
\hline \multirow{3}{*}{ Acteoside } & 5.0 & 75.51 & 8.03 & 99.00 & 12.97 & 9.41 & $0.95 \pm 0.06$ & 7.62 \\
\hline & 50.0 & 88.51 & 9.75 & 85.03 & 4.40 & 3.22 & $0.93 \pm 0.03$ & 3.11 \\
\hline & 800.0 & 97.14 & 3.43 & 86.70 & 6.21 & 8.97 & $0.92 \pm 0.02$ & 6.23 \\
\hline \multirow{3}{*}{ Isoacteoside } & 0.5 & 98.50 & 11.47 & 95.66 & 9.83 & 10.11 & $1.00 \pm 0.10$ & 7.96 \\
\hline & 5.0 & 70.56 & 1.48 & 89.52 & 6.38 & 3.98 & $1.02 \pm 0.09$ & 12.14 \\
\hline & 80.0 & 71.01 & 2.76 & 88.11 & 5.34 & 2.32 & $1.04 \pm 0.11$ & 2.35 \\
\hline \multirow{3}{*}{ Martynoside } & 1.0 & 104.54 & 12.41 & 89.27 & 12.66 & 4.78 & $0.96 \pm 0.05$ & 9.76 \\
\hline & 10.0 & 92.81 & 9.64 & 101.02 & 7.78 & 6.33 & $0.98 \pm 0.09$ & 4.12 \\
\hline & 160.0 & 98.19 & 4.14 & 96.23 & 3.42 & 5.22 & $0.99 \pm 0.08$ & 10.35 \\
\hline \multirow{3}{*}{ Crenatoside } & 1.0 & 82.96 & 11.42 & 85.31 & 2.34 & 10.90 & $1.00 \pm 0.08$ & 8.62 \\
\hline & 10.0 & 90.11 & 9.57 & 89.72 & 10.64 & 3.51 & $0.97 \pm 0.04$ & 10.69 \\
\hline & 160.0 & 80.38 & 5.33 & 106.66 & 4.47 & 2.96 & $0.90 \pm 0.03$ & 7.62 \\
\hline
\end{tabular}

The absolute matrix effects of these PhGs were from $85.03 \%$ to $106.66 \%$ (Table 5). And the relative standard deviation (RSD) values of relative matrix effects were less than $10.90 \%$. The IS normalized matrix factors were $0.90-1.04$. The above results indicated that the extraction recoveries of these PhGs were reliable, and there was almost no significant matrix effect in this experiment. 


\subsubsection{Stability}

The stability results of the four PhGs at three concentrations under four conditions are summarized in Table 6 . These four PhGs were observed to be stable under a variety of storage and process conditions with the RSD values less than $12.48 \%$ and the RE values from $-11.62 \%$ to $4.70 \%$.

Table 6. The stability of the four PhGs in rat plasma $(n=6)$.

\begin{tabular}{cccccccccc}
\hline \multirow{2}{*}{ Components } & \multirow{2}{*}{$\begin{array}{c}\text { Concentration } \\
(\mathbf{n g} / \mathbf{m L})\end{array}$} & \multicolumn{2}{c}{ Freeze and Thaw } & \multicolumn{2}{c}{ Short-Term } & \multicolumn{2}{c}{ Long-Term } & \multicolumn{2}{c}{ Post-Preparative } \\
\cline { 3 - 8 } & RSD (\%) & RE (\%) & RSD (\%) & RE (\%) & RSD (\%) & RE (\%) & RSD (\%) & RE (\%) \\
\hline \multirow{3}{*}{ Acteoside } & 5.0 & 2.92 & -1.58 & 2.17 & -5.26 & 2.51 & -2.45 & 4.68 & -2.72 \\
& 50.0 & 4.60 & -5.42 & 7.32 & -7.25 & 8.01 & -8.44 & 11.78 & 1.40 \\
& 800.0 & 6.32 & 1.50 & 7.04 & 4.70 & 6.49 & -0.01 & 2.27 & -2.16 \\
Isoacteoside & 0.5 & 6.59 & 0.61 & 7.53 & 2.98 & 7.43 & -1.42 & 9.61 & -2.70 \\
& 5.0 & 9.90 & -1.65 & 11.69 & 4.24 & 10.32 & 2.20 & 10.68 & 1.88 \\
& 80.0 & 1.99 & 0.61 & 6.28 & 2.98 & 6.06 & -1.42 & 7.32 & -2.70 \\
Martynoside & 1.0 & 9.46 & 3.03 & 9.09 & 2.04 & 8.74 & 1.27 & 7.47 & 2.27 \\
& 10.0 & 3.13 & -0.19 & 2.70 & -1.02 & 2.82 & -0.79 & 1.82 & -0.66 \\
& 160 & 1.13 & -2.71 & 1.47 & 1.44 & 1.69 & -0.91 & 2.47 & -0.60 \\
Crenatoside & 1.0 & 6.42 & 2.46 & 12.37 & -8.53 & 6.36 & 0.71 & 9.38 & -3.03 \\
& 10.0 & 10.87 & -8.98 & 10.42 & -5.32 & 9.94 & -11.6 & 12.48 & -10.95 \\
& 160 & 5.27 & -3.37 & 6.39 & -2.95 & 3.80 & -4.97 & 6.02 & -1.40 \\
\hline
\end{tabular}

\subsection{Pharmacokinetic Study}

The established and validated UPLC-MS/MS method was used to investigate the pharmacokinetics of AIH represented by the four PhGs in rat plasma after intragastric administration of AIH ethanol extract.

We found that all of the four PhGs could be detected from plasma at $5 \mathrm{~min}$ after intragastric administration of AIH ethanol extract (Figure 3). All of the PhGs showed double peaks on concentration-time curves. The first concentration peaks of all the PhGs appeared at about $0.5 \mathrm{~h}$, and then, reached the second peaks at approximately $6 \mathrm{~h}$ in rat plasma. Interestingly, a literature survey indicated that the concentration-time curve features of acteoside and isoacteoside have been reported as double peaks within $1 \mathrm{~h}$ in rat plasma after intragastric administration of individual components [25,26], whereas, they have been reported as single peaks $[27,28]$ or double peaks $[26,29]$ within $2 \mathrm{~h}$ when administrated medicinal plant extracts. In our study, the relatively distant double peaks of the PhGs might attribute to multiple reasons, such as the influences of complex compositions in $\mathrm{AIH}$, enterohepatic circulation, multiple absorption sites, and gastric emptying process.
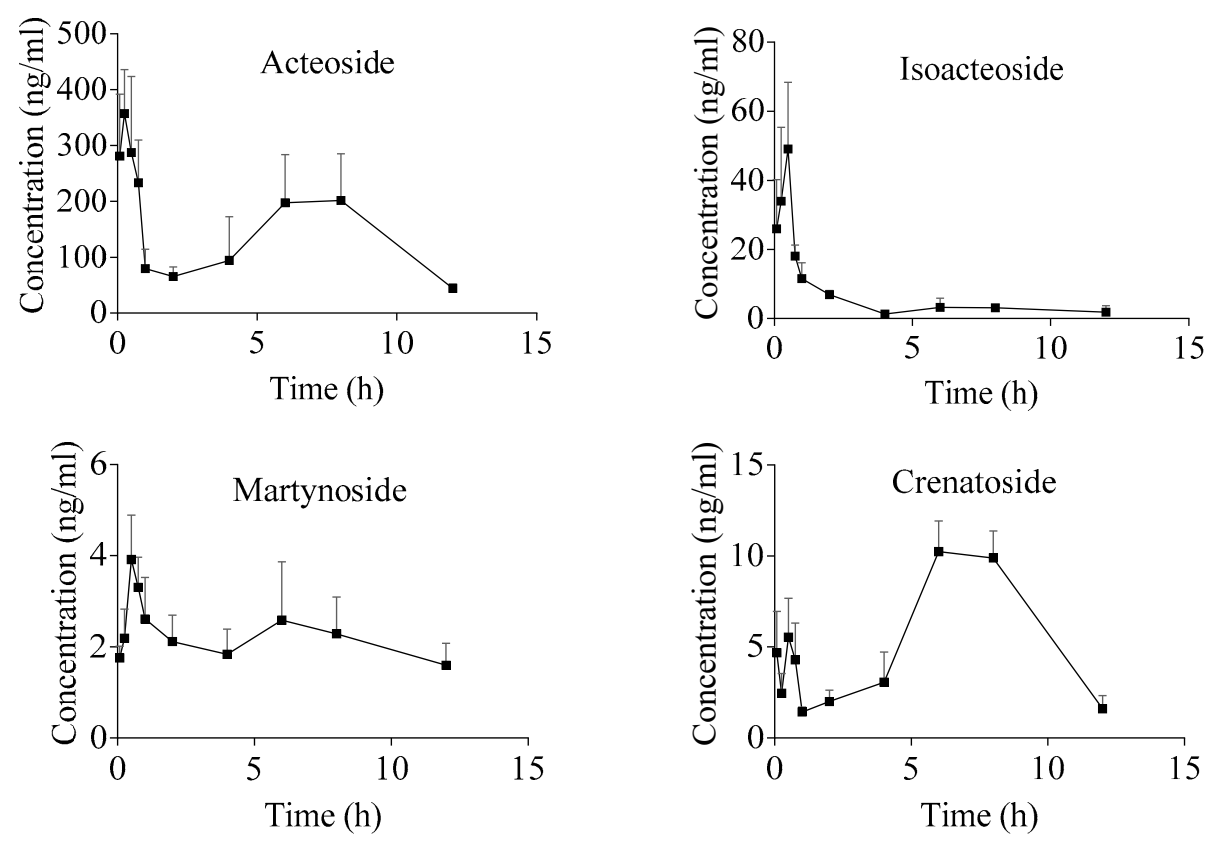

Figure 3. Mean plasma concentration-time curves of the four PhGs in rat plasma $(n=6)$. 
Among the four PhGs, the concentration of the second peak of crenatoside was higher than that of the first peak, but the concentration of the second peaks of the other three analytes were lower than those of their first peaks. The peak times $\left(t_{\max }\right)$ of acteoside and isoacteoside were at $0.3 \pm 0.1 \mathrm{~h}$ and $0.4 \pm 0.2 \mathrm{~h}$ (Table 7), respectively, which were consistent with previous studies [26,28-30]. The $t_{\max }$ of martynoside and crenatoside were at $3.1 \pm 3.6 \mathrm{~h}$ and $6.8 \pm 1.1 \mathrm{~h}$, respectively, which were longer than those of acteoside and isoacteoside.

Table 7. Pharmacokinetic parameters for the four PhGs in rat plasma after intragastric administration (means $\pm \mathrm{SD}, n=6$ ).

\begin{tabular}{ccccc}
\hline Parameter & Acteoside & Isoacteoside & Martynoside & Crenatoside \\
\hline $\mathrm{AUC}_{0-\mathrm{t}} /(\mu \mathrm{g} / \mathrm{L} \times \mathrm{h})$ & $1826.3 \pm 680.2$ & $70.9 \pm 26.9$ & $23.6 \pm 6.9$ & $64.7 \pm 14.5$ \\
$\mathrm{AUC}_{0-\infty} /(\mu \mathrm{g} / \mathrm{L} \times \mathrm{h})$ & $2243.1 \pm 894.6$ & $87.0 \pm 40.0$ & $39.5 \pm 15.5$ & $76.0 \pm 30.0$ \\
$\mathrm{t}_{1 / 2} /(\mathrm{h})$ & $5.6 \pm 3.4$ & $4.6 \pm 3.1$ & $9.0 \pm 2.7$ & $3.4 \pm 3.1$ \\
$\mathrm{t}_{\max } /(\mathrm{h})$ & $0.3 \pm 0.1$ & $0.4 \pm 0.2$ & $3.1 \pm 3.6$ & $6.8 \pm 1.1$ \\
$\mathrm{C}_{\max } /(\mu \mathrm{g} / \mathrm{L})$ & $356.9 \pm 64.2$ & $58.2 \pm 15.0$ & $4.0 \pm 0.9$ & $10.9 \pm 0.9$ \\
\hline
\end{tabular}

The areas under the curves $\left(\mathrm{AUC}_{0-\mathrm{t}}\right)$ of the four PhGs were consistent with their contents in $\mathrm{AIH}$, for example, acteoside exhibited the highest $\mathrm{AUC}_{0-\mathrm{t}}$ as $1826.3 \pm 680.2 \mu \mathrm{g} / \mathrm{L} \times \mathrm{h}$ and the highest content up to $6.24 \mathrm{mg} / \mathrm{g}$. The four PhGs displayed different elimination half-lives $\left(\mathrm{t}_{1 / 2}\right)$, ranging from $3.4 \mathrm{~h}$ to $9.0 \mathrm{~h}$, although they have similar molecular structures.

\section{Materials and Methods}

\subsection{Chemicals and Reagents}

The authentic phenylethanoid glycoside compounds were purchased as follows: acteoside (purity 98.0\%) from Dalian Meilun Biological Technology Co., Ltd. (Dalian, China); isoacteoside (purity 98.0\%) from Chengdu Push Bio-Technology Co., Ltd. (Chengdu, China); and genistein (internal standard, IS) from Shanghai Aladdin Biochemical Technology Co., Ltd. (Shanghai, China). Martynoside and crenatoside ( $>98.0 \%$ purity) were isolated from AIH in our laboratory and identified by combination of NMR, HPLC, and MS. HPLC-grade acetonitrile (MeCN) and methanol were purchased from Fisher Scientific Co., Ltd. (St. Louis, MO, USA). HPLC-grade formic acid was obtained from Shanghai Macklin Biochemical Co., Ltd. (Shanghai, China), and experimental water was purified by a Milli-Q Reagent Water System (Millipore, Burlington, MA, USA).

\subsection{Preparation of AIH Extracts}

The plant A. ilicifolius L. was collected from Jiangmen, Guangdong Province, China and authenticated by Professor Feng-Qin Zhou, Shandong University of Traditional Chinese Medicine. Voucher specimen number for A. ilicifolius L. is 2018060805. Voucher specimen of the plant is deposited at the Key Laboratory of Marine Drugs, the Ministry of Education of China, Ocean University of China, Qingdao, China.

The whole plant was dried in the shade and ground into crude powder. The crude powder $(200 \mathrm{~g})$ was immersed in $95 \%$ ethanol $(v / w, 10: 1)$ for $1 \mathrm{~h}$, and then heated to reflux at $80{ }^{\circ} \mathrm{C}$ for $2 \mathrm{~h}$. The extraction solution was filtered, and the residue was refluxed again in $95 \%$ ethanol $(v / w, 8: 1)$ at $80^{\circ} \mathrm{C}$ for $2 \mathrm{~h}$. The filtrate was pooled together and concentrated by a rotary evaporator to dryness at $45^{\circ} \mathrm{C}$. Finally, the product was dissolved in distilled water to acquire the AIH extract for testing with the concentration of $5.0 \mathrm{~g}$ crude herb $/ \mathrm{mL}$. This extract sample was stored at $4{ }^{\circ} \mathrm{C}$ until use.

\subsection{Animals}

Ten male Sprague-Dawley (250-280 g) rats were purchased from Jinan Pengyue Experimental Animal Center (SCXK (Lu) 20140007). The animal experiments were approved by the Animal Ethics 
Committee of Marine Biomedical Research Institute of Qingdao (MBRI-2018-0606), and the guidelines of the institute were strictly followed. All rats had free access to water and food, and were maintained in an environmentally controlled breeding room under the following conditions: $20 \pm 2{ }^{\circ} \mathrm{C}$ temperature, $60-70 \%$ relative humidity, and $12 \mathrm{~h}$ light/dark for 1 week before the experiment operated. After fasted for $12 \mathrm{~h}$ with free access to water, blank plasma was obtained from four rats after intragastric administration of $2.0 \mathrm{~mL} / \mathrm{kg}$ water for the UPLC-MS/MS method validation, and the other six rats which were administrated with AIH extract were used for the pharmacokinetic study as in Section 2.4.

\subsection{Preparation of Stock Solutions, Calibration Samples, and Quality Control Samples}

The stock solutions of four PhGs, acteoside, isoacteoside, martynoside, and crenatoside, were prepared with methanol as a solvent. A stock solution of the PhGs mixture was prepared by combining these four PhGs to attain the final concentrations of 10,000 ng/mL acteoside, $1000 \mathrm{ng} / \mathrm{mL}$ isoacteoside, $2000 \mathrm{ng} / \mathrm{mL}$ martynoside, and $2000 \mathrm{ng} / \mathrm{mL}$ crenatoside. The working solutions were obtained from the stock solution by sequential dilution with methanol at the concentrations of $20.0-10,000 \mathrm{ng} / \mathrm{mL}$ acteoside, $2.0-1000 \mathrm{ng} / \mathrm{mL}$ isoacteoside, $4.0-2000 \mathrm{ng} / \mathrm{mL}$ martynoside, and $4.0-2000 \mathrm{ng} / \mathrm{mL}$ crenatoside. Calibration samples were prepared by adding $5 \mu \mathrm{L}$ working solutions to $45 \mu \mathrm{L}$ blank plasmas in $1.5 \mathrm{~mL}$ Eppendorf tubes. Therefore, the final calibration samples contained $2.0-1000 \mathrm{ng} / \mathrm{mL}$ acteoside, $0.2-100 \mathrm{ng} / \mathrm{mL}$ isoacteoside, $0.4-200 \mathrm{ng} / \mathrm{mL}$ martynoside, and $0.4-200 \mathrm{ng} / \mathrm{mL}$ crenatoside. The quality control (QC) samples were prepared in the same way as calibration samples, with the final dilutions of 5.0, 50, and $800 \mathrm{ng} / \mathrm{mL}$ acteoside, $0.5,5$, and $80 \mathrm{ng} / \mathrm{mL}$ isoacteoside, 1.0, 10, and $160 \mathrm{ng} / \mathrm{mL}$ martynoside, and 1.0, 10, and $160 \mathrm{ng} / \mathrm{mL}$ crenatoside. The stock solution of the internal standard (IS), geistein, was prepared in methanol at the concentration of $1.0 \mathrm{mg} / \mathrm{mL}$. The IS working solution of $1000 \mathrm{ng} / \mathrm{mL}$ was obtained by diluting the stock solution with methanol.

\subsection{Pretreatment of Calibration Samples and QC Samples}

The $10 \mu \mathrm{L}$ IS working solution and $140 \mu \mathrm{L}$ methanol were added to each calibration sample $(50 \mu \mathrm{L})$ and QC sample $(50 \mu \mathrm{L})$. The mixture was vortexed for $60 \mathrm{~s}$ and centrifuged at $15,000 \times g$ for $15 \mathrm{~min}$ to separate the precipitated protein. Then, $2 \mu \mathrm{L}$ of supernatant of the mixture was used for the UPLC-MS/MS analysis.

\subsection{Instrumentation and Chromatographic Conditions}

A Waters ACQUITY'TM UPLC system (Waters Corp., Milford, MA, USA) was interfaced with a Waters $\mathrm{Xevo}^{\mathrm{TM}} \mathrm{TQ} / \mathrm{MS}$ (Waters, USA) equipped with an electrospray ionization (ESI) source. Separation of the PhGs was performed on an ACQUITY UPLC BEH C 18 column $(2.1 \times 50 \mathrm{~mm}, 1.7 \mu \mathrm{m})$, and the column temperature was maintained at $40{ }^{\circ} \mathrm{C}$ during the analysis. The mobile phase consisted of $\mathrm{MeCN}$ (solvent $\mathrm{A}$ ) and $0.1 \%$ formic acid in water (solvent $\mathrm{B}$ ) at a flow rate of $0.4 \mathrm{~mL} / \mathrm{min}$. The gradient elution conditions were as follows: $0-1 \mathrm{~min}, 2-2 \% \mathrm{~A} ; 1-1.5 \mathrm{~min}, 2-10 \% \mathrm{~A} ; 1.5-7 \mathrm{~min}, 10-43 \% \mathrm{~A}$; $7-8 \mathrm{~min}, 43-95 \%$ A; $8-9 \mathrm{~min}, 95 \%$ A; $9-10 \mathrm{~min}, 95-2 \%$ A. The injection volume was $2 \mu \mathrm{L}$. The detection wavelength was at $330 \mathrm{~nm}$.

The PhGs were detected and quantified by multiple reaction monitoring (MRM) in negative ionization mode $\left(\mathrm{ESI}^{-}\right)$. The MS parameters of the ionization source were as follows: source temperature, $150{ }^{\circ} \mathrm{C}$; capillary voltage, $3.15 \mathrm{kV}$; desolvation gas temperature, $400{ }^{\circ} \mathrm{C}$; desolvation gas flow rate, $800 \mathrm{~L} / \mathrm{h}$; and cone gas flow rate, $150 \mathrm{~L} / \mathrm{h}$. Other optimized parameters, collision energies, and cone voltages are shown in Table 1. All raw data were processed using MassLynx V4.1 workstation (Waters Corp., Milford, MA, USA).

\subsection{Method Validation}

The selectivity of the method was assessed by chromatograms of blank plasma, blank plasma spiked with working solution of the four PhGs at the lowest limit of quantification (LLOQ) together 
with working solution of IS, and test plasma acquired at $30 \mathrm{~min}$ after intragastric administration of AIH extract. The samples were prepared and pretreated in the same approaches as in Sections 3.4 and 3.5.

Various concentrations of calibration standards $(2.0,5.0,10,25,50,100,200,400,800$, and $1000 \mathrm{ng} / \mathrm{mL}$ acteoside; $0.2,0.5,1.0,2.5,5.0,10,20,40,80$, and $100 \mathrm{ng} / \mathrm{mL}$ isoacteoside; and 0.4, 1.0, $2.0,5.0,10,20,40,80,160$, and $200 \mathrm{ng} / \mathrm{mL}$ martynoside and crenatoside) were processed according to the above procedures for sample preparation. The calibration curve was constructed by plotting analyte-to-IS peak area ratio (y) versus the concentration $(x, n g / m L)$ of analyte and fitted to linear regression $(y=a x+b)$ using $1 / x$ as the weighting factor. The calibration curves were acceptable only if their correlation coefficients $\left(r^{2}\right)$ represented linearity of 0.99 or greater. The calibration curve was established daily throughout the method development and pharmacokinetic analysis. The LLOQ was determined by testing the lowest analytical concentration of the calibration curve.

The accuracy and precision of the method were evaluated by analyzing QC samples at three concentrations prepared as in Section 3.4 with six replicates. To determine the intra- and inter-day accuracy and precision, six replicates at each concentration level were analyzed for five consecutive days. Accuracy was expressed as relative error (RE, \%) values within $\pm 15 \%$, and precision was described as relative standard deviation (RSD, \%) values less than $15 \%$.

The extraction recoveries at different $Q C$ levels were investigated by comparing the mean peak areas of the PhGs pipetted into blank plasma before and after protein precipitation, respectively. The absolute matrix effect expressed as matrix factor (MF) was evaluated by comparing the peak areas of the PhGs pipetted into rat plasma after protein precipitation with those dissolved in the initial mobile phase solution. The relative matrix effect was assessed based on the peak areas of the PhGs pipetted into six different individual sources of rat plasma. The IS normalized MF was determined by the absolute MF of analyte over that of the IS.

The stabilities of the four PhGs were determined by using QC samples in different conditions. Freeze-thaw stability was assessed after three freeze-thaw cycles (from $-80{ }^{\circ} \mathrm{C}$ to room temperature). Short-term stability was determined after exposure of the QC samples at room temperature $\left(25^{\circ} \mathrm{C}\right)$ for $10 \mathrm{~h}$. Long-term stability was assessed by exposing the samples at $-20^{\circ} \mathrm{C}$ for 20 days. The samples stored in the autosampler at $4{ }^{\circ} \mathrm{C}$ for $24 \mathrm{~h}$ were used to evaluate the post-preparative stability. Each QC concentration level was prepared in six replicate samples.

\subsection{Pharmacokinetic Study}

AIH extract was given to the six rats at a dose of $10.0 \mathrm{~g}$ crude herb/kg body weight by intragastric administration. Blood samples $(200 \mu \mathrm{L})$ were collected from the fossa orbitalis vein before dosing and at the time points of 5, 15,30, and $45 \mathrm{~min}$ and 1, 2, 4, 6, 8, and $12 \mathrm{~h}$ after administration and transformed into heparinized Eppendorf tubes. Then, the blood samples were centrifuged at $12,000 \times g, 4{ }^{\circ} \mathrm{C}$, for 10 min. Each rat plasma sample $(50 \mu \mathrm{L})$ was prepared in the same approaches as in Section 3.5.

\subsection{Data Analysis}

Drug and Statistics (DAS) 3.2.8 software (Shanghai University of Traditional Chinese Medicine, Shanghai, China) was applied to calculate the pharmacokinetic parameters $\left(t_{1 / 2}, t_{\max }, C_{\max }, \mathrm{AUC}_{0-\mathrm{t}}\right.$, and $\mathrm{AUC}_{0-\infty}$ ) of the four PhGs. All data were shown as mean \pm standard deviation (SD).

\section{Conclusions}

In this study, an accurate and sensitive UPLC-MS/MS method was established and validated for the simultaneously quantitative determination of four PhGs (acteoside, isoacteoside, martynoside, and crenatoside) in rat plasma. This method which was specific to PhGs had good linearity, high accuracy and precision, and no significant matrix effect. By the established method, the preliminary pharmacokinetic features were firstly elucidated for AIH represented by the four PhGs in rats after intragastric administration of AIH extract. It was concluded that these four PhGs manifested relatively distant double peaks on the concentration-time curves and different elimination half-lives although 
they shared similar molecular structures. The achieved pharmacokinetic parameters may provide primary data and a scientific basis for the further research on the pharmacokinetics of AIH.

Author Contributions: Conceptualization, M.Z. and S.Y.; methodology, M.Z. and X.R.; software, S.Y.; validation, M.Z., X.R., and S.Y.; formal analysis, M.Z. and X.R.; investigation, M.Z.; resources, X.R.; data curation, M.Z. and X.R.; writing—original draft preparation, M.Z. and X.R.; writing—review and editing, M.Z., X.R., Q.Z., and C.W.; visualization, C.W. and C.S.; supervision, C.W. and C.S.; project administration, C.W. and C.S.; and funding acquisition, C.W. and C.S.

Funding: This work was financially supported by the National Natural Science Fund of China (Nos. 41806191 and U1606403), the National High Technology Research and Development Program of China (863 Program) (No. 2013AA093001), the project supported by the Marine S\&T Fund of the Shandong Province for Pilot National Laboratory for Marine Science and Technology (Qingdao) (No. 2018SDKJ0406-5), the Natural Science Foundation of Shandong Province (No. ZR2019BD049), and the Taishan Scholars Program, China.

Acknowledgments: We wish to acknowledge Dan Yan, the Capital Medical University, and Juan Liu, master student at the Capital Medical University for their kindness and help in the technical support.

Conflicts of Interest: The authors declare no conflict of interest.

\section{References}

1. Nanjing University of Chinese Medicine. Dictionary of Chinese Herbal Medicine; Shanghai Science and Technology Press: Shanghai, China, 1977; pp. 844-845.

2. Guan, H.S.; Wang, S.G. Chinese Marine Materia Medica; Shanghai Scientific and Technical Publishers: Shanghai, China, 2009; Volume 2, pp. 371-372.

3. Guan, H.S.; Wang, S.G. Selection of Chinese Marine Materia Medica; Shanghai Scientific and Technical Publishers: Shanghai, China, 2013; pp. 96-98.

4. Guan, H.S.; Wang, S.G. Illustrated Handbook of Chinese Marine Materia Medica; Shanghai Scientific and Technical Publishers: Shanghai, China, 2015; Volume 1, pp. 228-231.

5. Fu, X.M.; Zhang, M.Q.; Shao, C.L.; Li, G.Q.; Bai, H.; Dai, G.L.; Chen, Q.W.; Kong, W.; Fu, X.J.; Wang, C.Y. Chinese Marine Materia Medica Resources: Status and Potential. Mar. Drugs 2016, 14, 46. [CrossRef] [PubMed]

6. Babu, B.H.; Shylesh, B.S.; Padikkala, J. Antioxidant and hepatoprotective effect of Acanthus ilicifolius. Fitoterapia 2001, 72, 272-277. [CrossRef]

7. Babu, B.H.; Shylesh, B.S.; Padikkala, J. Tumour reducing and anticarcinogenic. activity of Acanthus ilicifolius in mice. J. Ethnopharmacol. 2002, 79, 27-33. [CrossRef]

8. Kumar, K.T.M.S.; Gorain, B.; Roy, D.K.; Samanta, S.K.; Pal, M.; Biswas, P.; Roy, A.; Adhikari, D.; Karmakar, S.; Sen, T. Anti-inflammatory activity of Acanthus ilicifolius. J. Ethnopharmacol. 2008, 120, 7-12. [CrossRef] [PubMed]

9. Kalaskar, P.S.; Karande, V.V.; Bannalikar, A.S.; Gatne, M.M. Antifungal activity of leaves of mangroves plant Acanthus ilicifolius against Aspergillus fumigatus. Indian J. Pharm. Sci. 2012, 74, 575-579. [CrossRef]

10. Firdaus, M.; Prihanto, A.A.; Nurdiani, R. Antioxidant and cytotoxic activity of Acanthus ilicifolius flower. Asian Pac. J. Trop. Biomed. 2013, 3, 17-21. [CrossRef]

11. Wahidulla, S.; Bhattacharjee, J.J. Benzoxazinoids from Acanthus ilicifolius. J. Indian Inst. Sci. 2001, 81, 485-490.

12. Kanchanapoom, T.; Kamel, M.S.; Kasai, R.; Yamasaki, K.; Picheansoonthon, C.; Hiraga, Y. Benzoxazinoid glucosides from Acanthus ilicifolius. Phytochemistry 2001, 58, 637-640. [CrossRef]

13. Kanchanapoom, T.; Kamel, M.S.; Kasai, R.; Yamasaki, K.; Picheansoonthon, C.; Hiraga, Y. Lignan glucosides from Acanthus ilicifolius. Phytochemistry 2001, 56, 369-372. [CrossRef]

14. Kanchanapoom, T.; Kasai, R.; Yamasaki, K. Flavonoid glycosides from Acanthus ilicifolius L. Nat. Med. 2002, 56,122

15. Wu, J.; Zhang, S.; Huang, J.; Xiao, Q.; Li, Q.; Long, L. Phenylethanoid and aliphatic alcohol glycosides from Acanthus ilicifolius. Phytochemistry 2003, 63, 491-495. [CrossRef]

16. Wu, J.; Huang, J.S.; Xiao, Q.; Zhang, S.; Xiao, Z.H.; Li, Q.X.; Long, L.J.; Huang, L.M. Complete assignments of ${ }^{1} \mathrm{H}$ and ${ }^{13} \mathrm{C}$ NMR data for 10 phenylethanoid glycosides. Magn. Reson. Chem. 2004, 42, 659-662. [CrossRef] [PubMed] 
17. Van, K.P.; Quang, T.H.; Huong, T.T.; Nhung le, L.T.; Cuong, N.X.; Van, M.C. Chemical constituents of Acanthus ilicifolius L. and effect on osteoblastic MC3T3E1 cells. Arch. Pharm. Res. 2008, 31, 823-829.

18. Morikawa, T.; Pan, Y.; Ninomiya, K.; Imura, K.; Matsuda, H.; Yoshikawa, M.; Yuan, D.; Muraoka, O. Acylated phenylethanoid oligoglycosides with hepatoprotective activity from the desert plant Cistanche tubulosa. Bioorg. Med. Chem. 2010, 18, 1882-1890. [CrossRef] [PubMed]

19. Pan, Y.N.; Morikawa, T.; Ninomiya, K.; Imura, K.; Yuan, D.; Yoshikawa, M.; Muraoka, O. Bioactive constituents from Chinese nature medicines: Four new acylated phenylethanoid oligoglycosides, kankanosides J1, J2, K1 and K2 from stems of Cistanche tubulosa. Chem. Pharm. Bull. 2010, 58, 575-578. [CrossRef] [PubMed]

20. Li, Y.X.; Chen, Z.; Feng, Z.M.; Yang, Y.N.; Jiang, J.S.; Zhang, P.C. Hepatoprotective glycosides from Leonurus japonicus Houtt. Carbohydr. Res. 2012, 348, 42-46. [CrossRef] [PubMed]

21. Ma, Q.G.; Guo, Y.M.; Luo, B.M.; Liu, W.M.; Wei, R.R.; Yang, C.X.; Ding, C.H.; Xu, X.F.; He, M.H. Hepatoprotective phenylethanoid glycosides from Cirsium setosum. Nat. Prod. Res. 2016, 30, 1824-1829. [CrossRef]

22. Shen, T.; Li, X.Q.; Hu, W.C.; Zhang, L.J.; Xu, X.D.; Wu, H.F.; Ji, L.L. Hepatoprotective effect of phenylethanoid glycosides from Incarvillea compacta against $\mathrm{CCl}_{4}$-induced cytotoxicity in HepG2 cells. J. Korean Soc. Appl. Biol. Chem. 2015, 58, 617-625. [CrossRef]

23. Xue, Z.Z.; Yang, B. Phenylethanoid glycosides: Research advances in their phytochemistry, pharmacological activity and pharmacokinetics. Molecules 2016, 21, 991. [CrossRef]

24. U.S. Food and Drug Administration. (FDA) Guidance for Industry: Bioanalytical Method Validation. 2018. Available online: https:/www.fda.gov/ucm/groups/fdagov-public/@fdagovdrugs-gen/documents/ document/ucm070107.pdf (accessed on 24 May 2018).

25. Gan, P.; Huo, S.X.; Bai, P.; Li, G.; Peng, X.M.; He, Y.; Yan, M. Pharmacokinetics and tissue distribution of acteoside in rats. Chin. Pharm. Bull. 2014, 30, 417-420.

26. Feng, B.W.; Song, Y.G.; Xu, Q.M.; Xu, P.F.; Zeng, Q.; Shan, B.X.; Liu, K.Y.; Su, D. Simultaneous determination of savaside A, acteoside, and isoacteoside in rat plasma by UHPLC-MS/MS: Comparative pharmacokinetic and bioavailability characteristics of Monochasma savatieri via different routes of administration. J. Sep. Sci. 2018, 41, 4408-4418. [CrossRef] [PubMed]

27. Zheng, D.K.; Chen, W.K.; Ma, S.C.; Shao, J.; Wang, J.; Luo, Y.H. Simultaneous determination of three phenolic glycosides in Callicarpa nudiflora by UHPLC-MS methods and analysis of their pharmacokinetics in plasma of rats. Chin. Tradit. Herb. Drugs 2015, 46, 3533-3538. [CrossRef]

28. Zhao, M.; Qian, D.W.; Liu, P.; Shang, E.X.; Jiang, S.; Guo, J.M.; Su, S.L.; Duan, J.A.; Du, L.Y.; Tao, J.H. Comparative pharmacokinetics of catalpol and acteoside in normal and chronic kidney disease rats after oral administration of Rehmannia glutinosa extract. Biomed. Chromatogr. 2015, 29, 1842-1848. [CrossRef] [PubMed]

29. Li, Y.J.; Gan, L.; Li, G.Q.; Deng, L.; Zhang, X.S.; Deng, Y.L. Pharmacokinetics of plantamajoside and acteoside from Plantago asiatica in rats by liquid chromatography-mass spectrometry. J. Pharm. Biomed. Ana. 2014, 89, 251-256. [CrossRef] [PubMed]

30. Wen, Y.; Huo, S.; Zhang, W.; Xing, H.; Qi, L.; Zhao, D.; Li, N.; Xu, J.; Yan, M.; Chen, X. Pharmacokinetics, biodistribution, excretion and plasma protein binding studies of acteoside in rats. Drug Res. 2016, 66, 148-153. [CrossRef] [PubMed]

Sample Availability: Not available. 